\title{
An Experimental and Numerical Investigation of a Grid Composite Cylindrical Shell Subjected to Transverse Loading
}

\author{
Jafar Arashmehr - Gholam Hossein Rahimi - Seyed Fazel Rasouli \\ Tarbiat Modares University, Department of Mechanical Engineering, Iran
}

This paper presents an experimental and numerical study of a stiffened composite cylindrical shell with clamped-free boundary condition under transverse end loading. Electrical strain gauges were employed to measure the strains. Likewise a finite element analysis has been used to validate the experimental results. The finite element method (FEM) software used was ANSYS11. Fairly good agreements were observed between the numerical and the measured results. In addition, a comparison between the stiffened and unstiffened composite shell was carried out. It was found that the intersection of two stiffeners has an important effect in reducing Von Mises stress in the shell. Failure analysis based on Tsai-Wu failure theory was also performed. It was concluded that stiffening of the shell by helical stiffeners increases the load capacity considerably.

Keywords: grid composite structure, transverse loading, stress analysis, finite element analysis

\section{INTRODUCTION}

Composite materials are desirable in lightweight structures due to their high specific stiffness and strength. These materials have great importance in the aerospace and aircraft industries. The main reasons for the success of composite materials use in the aerospace industry are the high performance versus weight ratios that it is possible to achieve using these materials and the necessity of lowering the weight of the aircraft as much as possible in order to enhance its efficiency [1].

Use of stiffeners can lead to higher load resistance of a composite structure without much increase in weight [2]. The grid composite structure is made of stiffeners and skin and the stiffeners can be made of other materials like metal alloys [3]. The stiffening structures are either on the inner or the outer or both sides of the skin.

Recent research on grid composite structures has tended to concentrate on the axial loading while the structures are exposed to transverse loadings as well as axial loadings. This investigation attempts to study the grid composite cylindrical shell under transverse loadings, both experimentally and numerically.

In recent years, a series of studies on the grid composite cylindrical shell have been carried out by Rahimi et. al. [4] to [6].

In the present study, a stress analysis of the structure under a clamped-free boundary condition subjected to transverse end load has been carried out both experimentally and numerically. Following this, a finite element modeling was utilized to verify the experimental result. To our knowledge, no investigation of this kind has been previously reported.

\section{EXPERIMENTAL STUDY}

\subsection{Fabrication Process}

The specimen in this study was fabricated using a specially designed filament winding machine designed and built in Tarbiat Modares University as shown in Fig. 1. This machine executes a continuous procedure to fabricate the specimen in which the ribs are first made, the skin is immediately wound around it, and then the specimen is cured. This process ensures a solid fusion of the ribs to the skin. E-glass fibers and a room-temperature-curing resin epoxy matrix were used for the fabrication. The nominal mechanical properties of the material are presented in Table 1 [5].

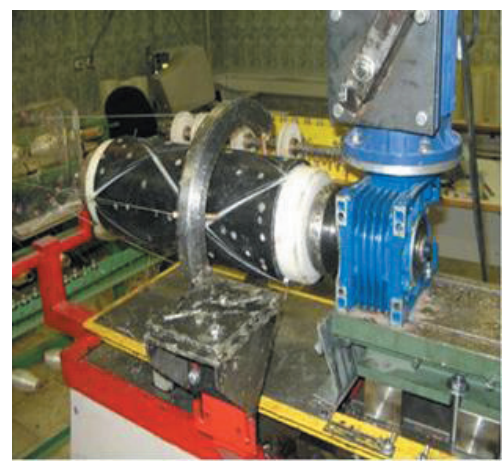

Fig. 1. Specimen fabrication using a filament winding process [4]

Table 1. Nominal material properties

\begin{tabular}{lccc}
\hline Material properties & Symbol & Unit & E-glass/Epoxy \\
\hline Longitudinal modulus & $E_{11}$ & {$[\mathrm{GPa}]$} & 36 \\
\hline Transverse modulus & $E_{22}$ & {$[\mathrm{GPa}]$} & 5.8 \\
\hline Transverse modulus & $E_{33}$ & {$[\mathrm{GPa}]$} & 5.8 \\
\hline Shear modulus & $G_{12}$ & {$[\mathrm{GPa}]$} & 3.22 \\
\hline Poisson's ratio & $v_{12}$ & {$[-]$} & 0.3 \\
\hline
\end{tabular}


The geometrical properties of the stiffened composite cylindrical shell are shown in Table 2:

Table 2. Geometrical properties of the stiffened composite cylindrical shell

\begin{tabular}{lc}
\hline Geometrical properties & Value \\
\hline Length & $31 \mathrm{~cm}$ \\
\hline Diameter & $14 \mathrm{~cm}$ \\
\hline Number of ribs & 6 \\
\hline Cross section's dimensions of ribs & $6 \times 6 \mathrm{~mm}$ \\
\hline Thickness of shell & $0.8 \mathrm{~mm}$ \\
\hline
\end{tabular}

The ribs form a 30 degrees angle with the axis of revolution of the cylindrical shell. It should be noted that the shape of the cross section of the stiffeners can change the results [7]. The fabricated specimen is shown in Fig. 2.

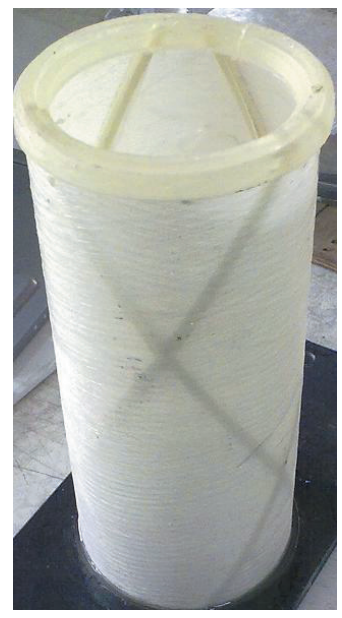

Fig. 2. A sample of the fabricated specimens

\subsection{Testing}

An L-shaped steel fixture was designed to mount the specimen on the testing machine. The specimen was installed in a circular groove created in the fixture. The steel sheet attached to the free end of the specimen provided distribution of the load onto the circumference of the edge of the shell and prevented local damage due to concentrated load. The stiffened shell was tested under clamped-free boundary conditions, with the load transversely exerted on the free end. Fig. 3 shows a sketch of the test.

For strain measurement, $120 \Omega$ strain gauges were employed [8]. Each gage must be bonded carefully to the structure. The strain gauges were attached to the top face of the specimen at four points (Three strain gauges at each point) in a rosette arrangement as shown in Fig. 4.

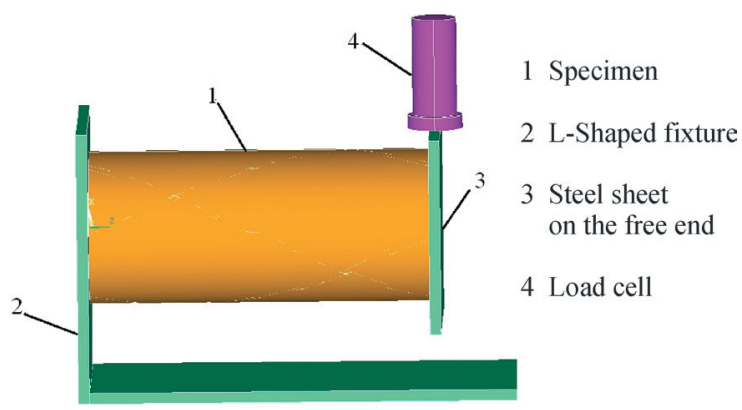

Fig. 3. Sketch of the specimen mounted on the fixture

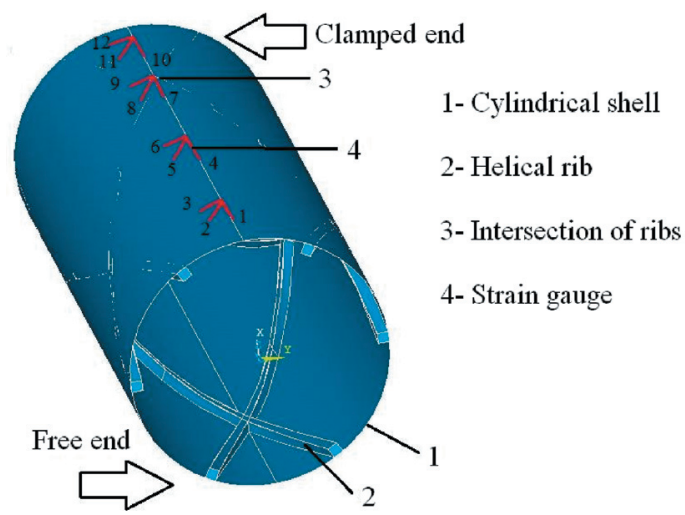

Fig. 4. Sketch of the bonding of the strain gauges on the top of the specimen

An INSTRON test machine was used to apply the load in a displacement-controlled procedure with a rate of $1 \mathrm{~mm} / \mathrm{min}$ [9]. Fig. 5 shows the stiffened composite shell during the test. The loading was continued until the structure failed from the clamped end. It should be mentioned that a marker was drawn under the load cell and on the steel sheet to see if there was any rotation in the shell or not. It was observed after the test that the marker did not have any horizontal displacement with respect to the load cell, which means that no rotation was found.

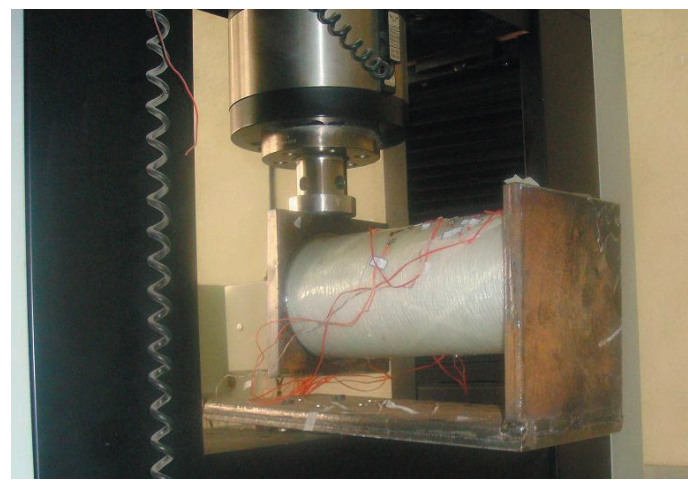

Fig. 5. The specimen under loading 


\section{FINITE ELEMENT MODELING}

ANSYS 11.0 software was employed to make a 3-D model of the structure [10]. The intersections of the ribs were modeled as distinct volumes with twice the fiber volume fraction as the ribs due to accumulation of fibers in these areas during the fabrication process.

The stiffeners were meshed using 20-node layered solid elements, SOLID191. Since the fibers are unidirectional within the ribs, the number of layers would not make any difference to the results. SHELL99 was used to mesh the shell [7]. It was found to be adequate to assume the shell to be a 20-ply laminate after a divergence test.

The nodes of the shell and the rib elements within a tolerance of 0.6 millimeters were coupled together in order to stick the shell and the ribs together.

The boundary conditions, including clamped-free and transverse end loading, were applied to the model. It should be noted that the weight of the steel sheet attached to the free end $(2 \mathrm{~kg})$, was considered in the FEM analysis. The created FEM model is presented in Fig. 6.

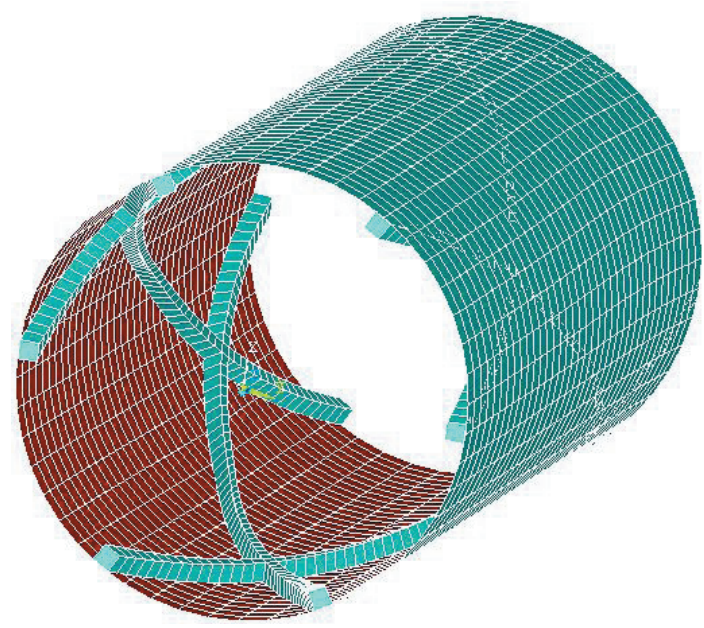

Fig. 6. The FEM Model

Static analysis was conducted to extract the strains and stresses along the top face of the stiffened shell.

\section{RESULTS}

The obtained results in $400 \mathrm{~N}$ of the experimental and numerical studies are shown in Table 3. The number of each strain gauge is shown in Fig. 4.

There is a good accordance between the results for both approaches. Fig. 7 shows the variations in the displacement of the free end versus the applied transverse end load obtained in the experiment.

Fig. 7 indicates $1700 \mathrm{~N}$ of load capacity for this structure under the mentioned boundary conditions. The behaviour of this structure changes linearly until approximately $1400 \mathrm{~N}$. After a $7 \mathrm{~mm}$ deflection of the free end, the first reduction in the load variation is observed. This is the time that buckling or collapse takes place in the structure. In the failure analysis part of this paper, it will be illustrated that the collapse in the composite shell occurs in this point. Following this, the load increases again up to the maximum load capacity.

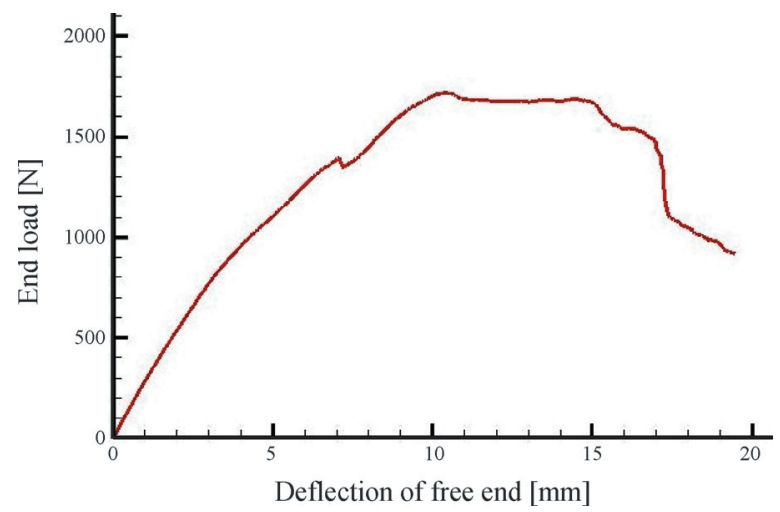

Fig. 7. Deflection of the free end versus the applied load

In this experiment $\varepsilon_{x}, \varepsilon_{y}$, were measured. By using Eq. (1), the $\gamma_{x y}$ is obtained:

$$
\varepsilon(\theta)=\varepsilon_{x} \cos ^{2} \theta+\varepsilon_{y} \sin ^{2} \theta+\gamma_{x y} \sin \theta \cos \theta,
$$

therefore

$$
\gamma_{x y}=\frac{\varepsilon(\theta)-\varepsilon_{x} \cos ^{2} \theta-\varepsilon_{y} \sin ^{2} \theta}{\sin \theta \cos \theta} .
$$

Table 3. Result of strains in experimental and numerical studies

\begin{tabular}{lcccccccccccc}
\hline Number of strain gauge & 1 & 2 & 3 & 4 & 5 & 6 & 7 & 8 & 9 & 10 & 11 & 12 \\
\hline Experimental (micro strain) & 867 & 56 & 19 & 1412 & 92 & 103 & 149 & -171 & -232 & 3022 & -283 & 18 \\
\hline FEM (micro strain) & 729 & 46 & 14 & 1208 & 69 & 79 & 122 & -133 & -187 & 2387 & -232 & 14 \\
\hline Difference [\%] & 19 & 17 & 26 & 16 & 25 & 23 & 18 & 22 & 24 & 21 & 18 & 22 \\
\hline
\end{tabular}




\subsection{Stress Distribution}

Considering that the strain gauges show the strains in the outer layer of the shell [11], and the fact that the shell is wound at a 75 degrees angle, a coordinate system transformation should be done prior to using stress-strain relations. This is shown in Fig. 8.

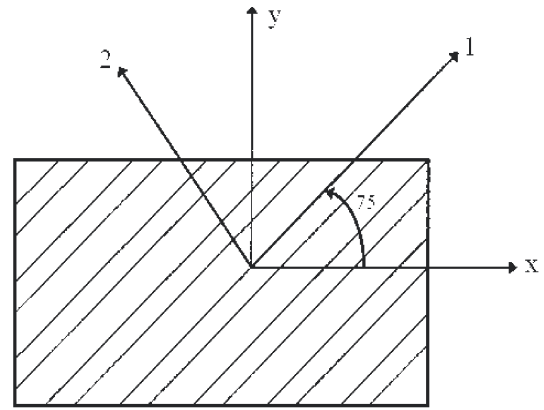

Fig. 8. Global and material coordinate systems

$$
\left[\begin{array}{c}
\sigma_{x} \\
\sigma_{y} \\
\tau_{x y}
\end{array}\right]=\left[\begin{array}{lll}
\overline{Q_{11}} & \overline{Q_{12}} & \overline{Q_{16}} \\
\overline{Q_{12}} & \overline{Q_{22}} & \overline{Q_{26}} \\
\overline{Q_{16}} & \overline{Q_{26}} & \overline{Q_{66}}
\end{array}\right]\left[\begin{array}{l}
\varepsilon_{x} \\
\varepsilon_{y} \\
\gamma_{x y}
\end{array}\right] .
$$

Where the transformed reduced stiffness $\bar{Q}_{i j}$ is given in terms of reduced stiffness $Q_{i j}$ in Eq. (4).

$\bar{Q}_{11}=n^{4} Q_{11}+2 m^{2} n^{2}\left(Q_{12}+2 Q_{66}\right)+m^{4} Q_{22}$,

$\bar{Q}_{12}=n^{2} m^{2}\left(Q_{11}+Q_{22}-4 Q_{66}\right)+\left(m^{4}+n^{4}\right) Q_{12}$,

$\bar{Q}_{16}=m n\left(n^{2}\left(Q_{11}-Q_{12}-2 Q_{66}\right)\right)+n m^{3}\left(Q_{12}-Q_{22}+2 Q_{66}\right)$,

$\bar{Q}_{22}=m^{4} Q_{11}+2 m^{2} n^{2}\left(Q_{12}+2 Q_{66}\right)+n^{4} Q_{22}$,

$\bar{Q}_{26}=m^{3}\left(n\left(Q_{11}-Q_{12}-2 Q_{66}\right)\right)+m n^{3}\left(Q_{12}-Q_{22}+2 Q_{66}\right)$,

$\bar{Q}_{66}=n^{2} m^{2}\left(Q_{11}-2 Q_{12}-2 Q_{66}+Q_{22}\right)+\left(n^{2}+m^{2}\right) Q_{66}$,

where $m=\sin \theta, n=\cos \theta$ and $\theta$ is the angle of the fibers and the axis of revolution of the shell.

For the orthotropic lamina, $Q_{i j}$ are:

$$
\begin{gathered}
Q_{11}=\frac{E_{1}}{1-v_{12} v_{21}}, \quad Q_{12}=\frac{v_{12} E_{2}}{1-v_{12} v_{21}}=Q_{21}, \\
Q_{22}=\frac{E_{2}}{1-v_{12} v_{21}}, \quad Q_{66}=G_{12} .
\end{gathered}
$$

It should be noted that the stresses were calculated at $400 \mathrm{~N}$. Looking back at the load-displacement graph, it is clear that at this load the structure is in the linear zone. The stresses in the experimental study are obtained from Eq. (3).

\subsection{Experimental versus Finite Element Results}

A comparison of the variation in $\sigma_{x}$ versus the distance from the free end between the experimental and finite element results is shown in Fig. 9:

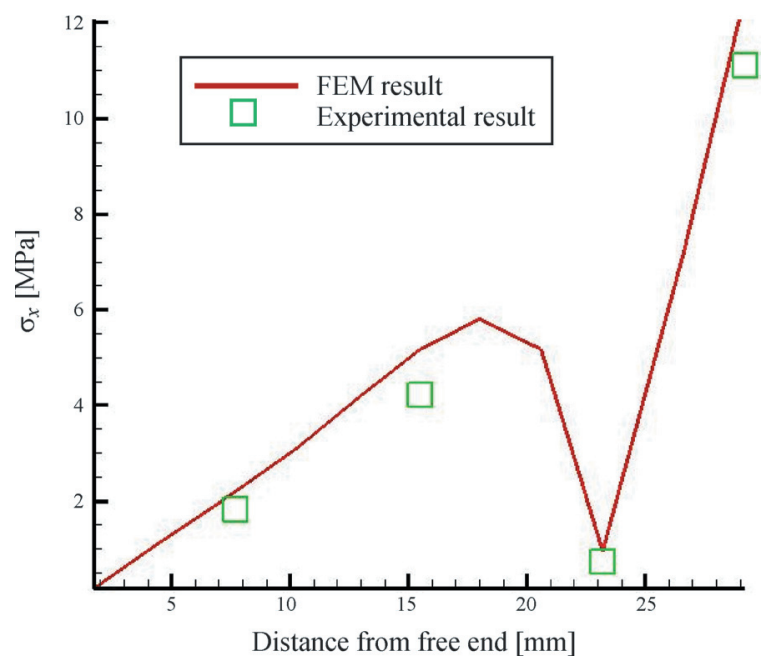

Fig. 9. $\sigma_{x}$-Finite element vs. experimental result comparison

Fig. 9 shows that at a distance of $23 \mathrm{~cm}$ from the free end of the cylinder which is the intersection point of the two ribs, the $\sigma_{x}$ considerably decreases in comparison with other points. It was also found that the values of the $\sigma_{y}, \tau_{x y}$ decrease noticeably at the intersection point of the two stiffeners as well as at $\sigma_{x}$.

The von Mises equivalent stress for plane-stress is obtained from Eq. (5) and the values of this stress for experimental and numerical analyses are compared in Fig. 10.

$$
\sigma_{\text {vonMises }}=\sqrt{\frac{\left(\sigma_{x}-\sigma_{y}\right)^{2}+\sigma_{x}{ }^{2}+\sigma_{y}{ }^{2}+6 \tau_{x y}{ }^{2}}{2}} .
$$

It is evident from the graph that the equivalent von Mises stress declines significantly at the intersection point of the stiffeners.

The deformed shape of the structure in the FEM analysis indicates that the decrease in the stresses at the abovementioned point is due to the deformation in the stiffened shell under the transverse end load. Fig. 11 shows the large scale deformed shape of the specimen. 


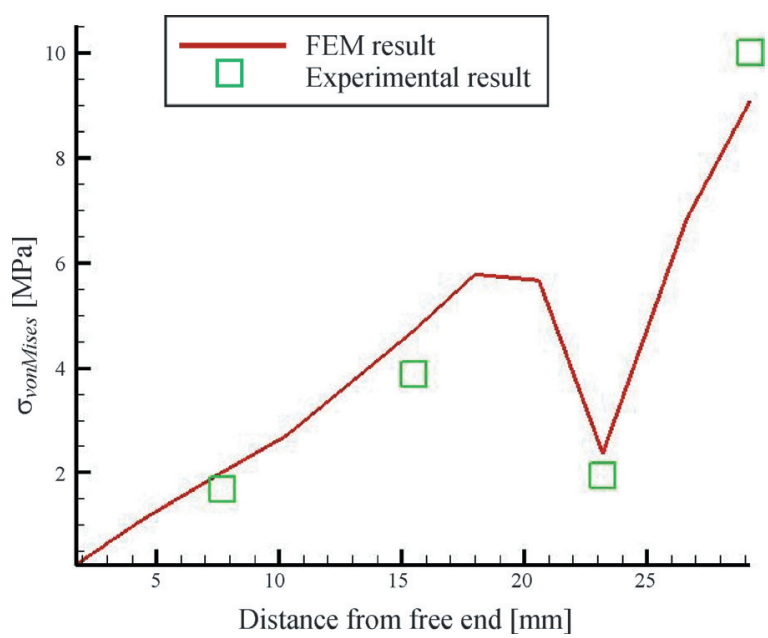

Fig. 10. $\sigma_{\text {vonMises }}$ - Finite element vs. experimental result comparison

The elements on the top face of the structure are expected to be in tension. As shown in Fig. 11, the deformation near the junction of two stiffeners on the top of the structure is remarkably less than that seen in other parts of the structure. In addition the contour of stress distribution in the stiffened shell illustrates a significant decrease in von Mises stress at this point (Fig. 12).

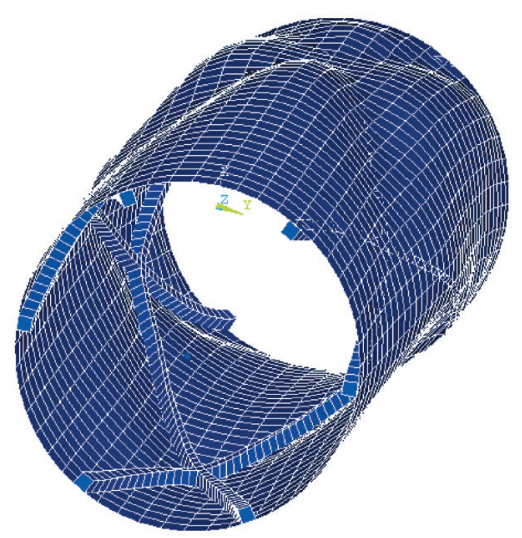

Fig. 11. Deformation of the structure

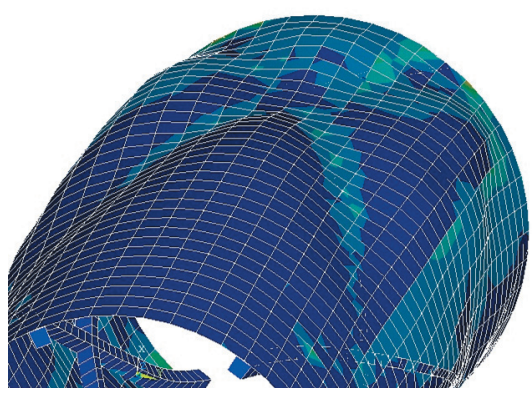

Fig. 12. von Mises stress distribution
To determine the effect of stiffening of a cylindrical composite shell, the stiffened composite shell is compared to an unstiffened composite shell.

\subsection{Stiffened Shell vs. Unstiffened Shell Result}

In this section, the obtained FE results are compared to the results of an unstiffened shell under the same boundary conditions. Therefore, a finite element model of an unstiffened composite shell with the same material properties was built [13].

Fig. 13 shows a comparison of the variations in the $\sigma_{\text {vonMises }}$ between the stiffened shell and the unstiffened shell under the same boundary conditions.

It is concluded that the greatest difference in von Mises stress is at a distance $23 \mathrm{~cm}$ from the free end of the structure. This is where the junction of the two stiffeners is located in the stiffened shell. The above graph shows lower values of von Mises stress in the stiffened shell compared to the unstiffened shell.

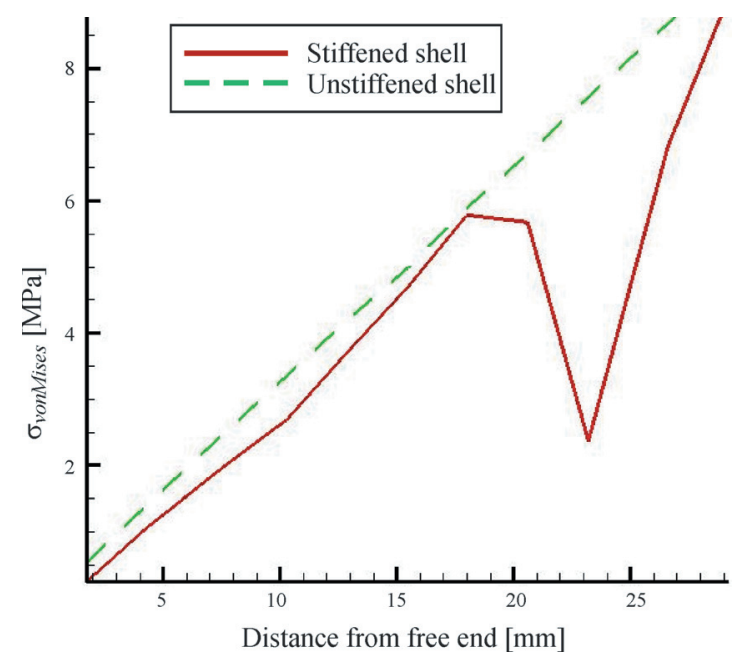

Fig. 13. $\sigma_{\text {vonMises }}$ - stiffened vs. unstiffened composite shell

\section{FAILURE ANALYSIS}

Grid composite structures have different failure modes that strongly depend on the type of loading and boundary conditions. The stiffened composite shell may fail due to some mechanism such as collapse of the stiffeners or skin. It was observed from the experiments that the stiffened composite cylindrical shell would finally fail in the clamped end. This failure mode occurs in the shell. Fig. 14 shows the failure of the structure.

In addition, no other failure modes in other parts of the stiffeners or the shell were observed. However, other failure modes like collapse of the stiffener are 
possible in other types of loading, such as local loads [14]. The Tsai-Wu failure theory failure theory is used for the failure analysis [15]. Two methods were applied to the failure analysis. In the first approach, the experimental results near the clamped end and the Tsai-Wu failure theory are employed. The values of $\sigma_{x}, \sigma_{y}$ and $\tau_{x y}$ are obtained from Eq. (7). These stresses are in a global coordinate system, which is needed to calculate them in the material coordinate system.

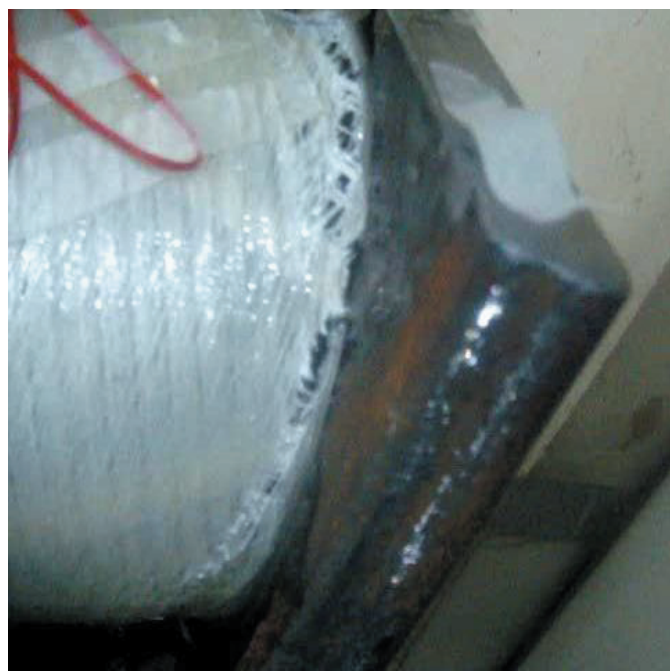

Fig . 14. Failure of the structure in the clamped end under a transverse end load

The global and local stresses in an angle lamina are related to each other through the angle of the lamina, $\theta$ :

$$
\left[\begin{array}{c}
\sigma_{1} \\
\sigma_{2} \\
\tau_{12}
\end{array}\right]=[T]\left[\begin{array}{l}
\sigma_{x} \\
\sigma_{y} \\
\tau_{x y}
\end{array}\right],
$$

where $[T]$ is defined as:

$$
[T]=\left[\begin{array}{ccc}
\cos ^{2} \theta & \sin ^{2} \theta & 2 \sin \theta \cos \theta \\
\sin ^{2} \theta & \cos ^{2} \theta & -2 \sin \theta \cos \theta \\
-\sin \theta \cos \theta & \sin \theta \cos \theta & \cos ^{2} \theta-\sin ^{2} \theta
\end{array}\right],
$$

where $\theta=75^{\circ}$.

Therefore the results of point 4 which is near the clamped end are used for the calculation of the required stresses in the material coordinate system.

The Tsai-Wu failure theory is defined as:

$$
\begin{gathered}
H_{1} \sigma_{1}+H_{2} \sigma_{2}+H_{6} \tau_{12}+H_{11} \sigma_{1}^{2}+ \\
+H_{22} \sigma_{2}^{2}+H_{66} \tau_{12}^{2}+2 H_{12} \sigma_{1} \sigma_{22}<1,
\end{gathered}
$$

where [16]

$$
\begin{gathered}
H_{1}=\frac{1}{\left(\sigma_{1}^{T}\right)_{u l t}}-\frac{1}{\left(\sigma_{1}^{C}\right)_{u l t}}, \quad H_{11}=\frac{1}{\left(\sigma_{1}^{T}\right)_{u l t}\left(\sigma_{1}^{C}\right)_{u l t}}, \\
H_{2}=\frac{1}{\left(\sigma_{2}{ }^{T}\right)_{u l t}}-\frac{1}{\left(\sigma_{2}{ }^{C}\right)_{u l t}}, \quad H_{22}=\frac{1}{\left(\sigma_{2}^{T}\right)_{u l t}\left(\sigma_{2}{ }^{C}\right)_{u l t}}, \\
H_{6}=0, \quad H_{12}=-\frac{1}{2} \sqrt{\frac{1}{\left(\sigma_{1}^{T}\right)_{u l t}\left(\sigma_{1}^{C}\right)_{u l t}\left(\sigma_{2}^{T}\right)_{u l t}\left(\sigma_{2}{ }^{C}\right)_{u l t}}}, \\
H_{66}=\frac{1}{\left(\tau_{12}\right)_{u l t}^{2}} .
\end{gathered}
$$

The ultimate strengths of the e-glass fibers is presented in Table 4: [17]

Table 4. Properties of unidirectional e-glass fibers

\begin{tabular}{lcc}
\hline Parameter & Unit & Value \\
\hline$\left(\sigma_{1}^{T}\right)_{u l t}$ & {$[\mathrm{MPa}]$} & 1080 \\
\hline$\left(\sigma_{2}^{T}\right)_{u l t}$ & {$[\mathrm{MPa}]$} & 39 \\
\hline$\left(\sigma_{1}\right)_{\text {ult }}$ & {$[\mathrm{MPa}]$} & 620 \\
\hline$\left(\sigma_{2}\right)_{u l t}$ & {$[\mathrm{MPa}]$} & 128 \\
\hline$\left(\tau_{12}\right)_{\text {ult }}$ & {$[\mathrm{MPa}]$} & 89 \\
\hline$\left(\varepsilon_{1}^{T}\right)_{u l t}$ & {$[-]$} & 0.028 \\
\hline$\left(\varepsilon_{2}^{T}\right)_{u l t}$ & {$[-]$} & 0.005 \\
\hline
\end{tabular}

Table 5. Failure analysis results

\begin{tabular}{ccccccccc}
\hline \multirow{2}{*}{$\begin{array}{c}\text { Load } \\
{[\mathrm{N}]}\end{array}$} & \multicolumn{2}{c}{$\sigma_{1}[\mathrm{MPa}]$} & \multicolumn{2}{c}{$\sigma_{2}[\mathrm{MPa}]$} & \multicolumn{2}{c}{$\tau_{12}[\mathrm{MPa}]$} & \multicolumn{2}{c}{$\begin{array}{c}\text { Tsai-Wu failure } \\
\text { theory index }\end{array}$} \\
\cline { 2 - 9 } & FEM & EXP & FEM & EXP & FEM & EXP & FEM & EXP \\
\hline 400 & 6.4 & 5.24 & 13.17 & 10.53 & 0.26 & 0.2 & 0.222 & 0.196 \\
\hline 800 & 12.81 & 10.76 & 26.53 & 21.75 & 0.486 & 0.383 & 0.495 & 0.460 \\
\hline 1450 & 22.92 & 19.71 & 47.4 & 39.34 & 0.78 & 0.631 & 1.021 & 0.952 \\
\hline
\end{tabular}

In the second step, finite element failure analysis is carried out based on the Tsai-Wu failure theory [18]. The failure criterion was defined using the ultimate strengths in Table 4.

Both methods were carried out for three different loads and the results are presented in Table 5.

The results show a good agreement between both methods. It should be noted that FEM analysis also shows that the stiffened composite cylindrical shell will fail at the clamped edge as observed in the experiments. The failure load of the structure was found to be $1465 \mathrm{~N}$ in the experimental methods and $1437 \mathrm{~N}$ in the FEM failure analysis.

On the other hand in the Load-Displacement graph (Fig. 7), at $1394 \mathrm{~N}$ the load decreases temporarily and 
the increases again. This is where the failure occurs in the clamped end of the stiffened shell.

Afterwards, FEM failure analysis was carried out for an unstiffened shell using the same boundary conditions. The result clarified that the unstiffened shell fails in the clamped end similarly to the stiffened shell. The failure load for the unstiffened composite shell was found to be $1215 \mathrm{~N}$, which is about $17 \%$ lower than the load capacity of the stiffened composite shell.

\section{CONCLUSION}

In this study, a stress analysis for a stiffened composite cylindrical shell under clamped-free boundary conditions subjected to a transverse end load was carried out using experimental and numerical methods. A failure analysis for the structure was also performed and the results were compared to the unstiffened composite shell. The most important conclusions are listed below:

- The effect of the intersection of the stiffeners can be used in some parts of the structure where a high level of stress is expected. For example this effect would be useful around areas where stress concentration exists.

- Under this load and these boundary conditions, the most important concern is related to the areas near the clamped end. In other words, the failure probability at this point is far higher than other points in the structure. This structure also protected against other failure modes including separation between the ribs and skin or collapse of the ribs.

- The failure analysis showed a 17\% higher load capacity in the stiffened composite shell compared to the unstiffened shell, which is undoubtedly a useful point in the design of these structures.

\section{APPENDIX}

Specimen Fabrication. The process of fabrication begins with laying the e-glass fibers within the predesigned grooves in the mandrel until reaching the desired number of fiber threads within a single groove, which was 100 threads for the specimens in this paper. The fibers are therefore uni-directional along the grooves (or eventually the stiffeners). After the grooves of the ribs were filled with the desired volume of fibers and resin, the shell was immediately wound as the mandrel rotated and also reciprocated and a stationary filler fed the fibers. The rotational and reciprocal speed of the mandrel was adjusted to obtain 72 degree fiber angles with respect to the axis of rotation of the cylinder. The process cannot define a definite number of layers for the fibers; therefore, the number of layers in the FEA was defined by a convergence test, which means that the number of layers were increased until the results reached an approximately constant point (20 layers for the shell and 1 layer for the fibers, since they are unidirectional). The fiber volume fraction was designed to be approximately $30 \%$. It should be mentioned that at the intersection of the stiffeners there are twice as many fibers as other sections of the stiffeners, which was modeled by doubling the volume fraction in the FEA model. The final geometrical properties are given in Table 2.

\section{REFERENCES}

[1] Jaunky, N., Knight, N., Ambur, D. (1998). Optimal design of general stiffened composite circular cylinders for global buckling with strength constraints. Journal of Composite Structures, vol. 41, no. 3-4, p. 243-252, DOI:10.1016/S0263-8223(98)00020-8.

[2] Wodesenbet, N., Kidane, S. (2003). Optimization for buckling loads of Grid stiffened composite panels. Journal of Composite structures, vol. 60, no. 2, p. 159169, DOI:10.1016/S0263-8223(02)00315-X.

[3] Huo, S., Yuan, Z., Wang, F., Yue, Z., Liu, Y. (2013). Effect of static aeroelasticity on composite wing characteristics under different flight attitudes. Journal of Central South University,vol. 20, no. 2, p. 312-317, DOI:10.1007/s11771-013-1489-8.

[4] Yazdani, M., Rahimi, G.H. (2009). An experimental investigation into the Buckling of GFRP stiffened shells under axial loading. Academic Journal, vol. 4, no. 9, p. 914-920.

[5] Rahimi, G.H., Yazdani, M. (2010). The effects of helical ribs' number and grid types on the buckling of thin-walled GFRP-stiffened shells under axial loading. Journal of Reinforced Plastics and Composites, vol. 29, no. 17, p. 2568-2575, DOI:10.1177/0731684409355202.

[6] Yazdani, M., Rahimi, G.H. (2011). The behavior of GFRP-stiffened and -unstiffened shells under cyclic axial loading and unloading. Journal of Reinforced Plastics and Composites, vol. 30, no. 5, p. 440-445, DOI:10.1177/0731684411398537.

[7] Rahimi, G.H., Zandi, M., Rasouli, S.F. (2013). Analysis of the effect of stiffener profile on buckling strength in composite isogrid stiffened shell under axial loading. Journal of Aerospace Science and Technology, vol. 24, no. 1, p. 198-203, DOI:10.1016/j.ast.2011.11.007.

[8] Arashmehr, J., Rahimi, G.H. (2012). Experimental investigation of clamped stiffened composite cylindrical shells under end load. Experimental Solid 
Mechanic and Dynamics Conference (xmech 2012), Tehran.

[9] Zheng, Z., Wang, J., Mi, L. (2010). Preparation of new tissue engineering bone-CPC/PLGA composite and its application in animal bone defects. Journal of Central South University, vol. 17, p. 202-210, DOI:10.1007/ s11771-010-0031-5.

[10] Movaghghar, A., Ivanovich Lvov, G. (2012). Theoretical and experimental study of fatigue strength of plain woven glass/epoxy composite. Strojniški vestnik - Journal of Mechanical Engineering, vol. 58, no. 3, p. 175-182, DOI:10.5545/sv-jme.2011.135.

[11] Li, G. (2007). Experimental study of hybrid composite cylinders. Composite Structures, vol. 78, no. 2, p. 170181, DOI:10.1016/j.compstruct.2005.08.028.

[12] Jones, R. (1999). Machromechanical behavior of a lamina a lamina. Mechanics of Composite Materials, Taylor\&Francis, Portland, p. 75-77.

[13] Arashmehr, J., Rahimi, G.H., Rasouli, S.F. (2012). Numerical and experimental stress analysis of stiffened cylindrical composite shell under transverse end load.
Journal of World Academy of Science, Engineering and Technology, vol. 67, p. 1298-1302.

[14] Arashmehr, J., Rahimi, G.H. (2012). Investigation of grid composite cylindrical shell under local load. 11th Conference of Iranian Aerospace Society, Tehran.

[15] Ilić, I., Petrovic, Z., Maksimović, M. (2012). Computation method in failure analysis of mechanically fastened joints at layered composites. Strojniški vestnik - Journal of Mechanical Engineering, vol. 58, no. 9, p. 553-559, DOI:10.5545/sv-jme.2011.157.

[16] Kaw, A. (2006). Micromechanical analysis of a lamina. Mechanics of Composite Materials, Taylor \& Francis, Portland, p. 137-158.

[17] Daniel, I. (1994). Elastic behavior of unidirectional lamina, Engineering Mechanic of Composite Materials, Oxford University, New York, p. 34

[18] Jadhav, P., Mantena, P. (2007). Parametric optimization of grid-stiffened composite panels for maximizing their performance under transverse loading. Composite Structures, vol. 77, p. 353-363, DOI:10.1016/j. compstruct.2005.07.015. 